\title{
THE GAP BETWEen THE KNOWLEDGE OF VIRTUAL ENTERPRISE ACTOR AND KNOWLEDGE DEMAND OF INDUSTRY 4.0
}

\author{
Anca Georgiana Costache (Stochitoiu), Cicerone Laurentiu Popa, \\ Tiberiu Dobrescu, Costel Emil Cotet
}
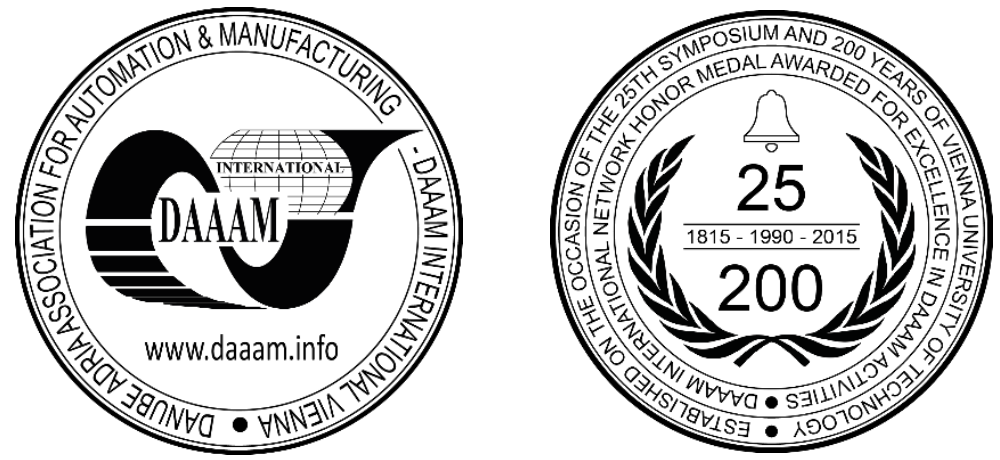

This Publication has to be referred as: Costache (Stochitoiu), A[nca] G[eorgiana]; Popa, C[icerone] L[aurentiu]; Dobrescu, T[iberiu] G[abriel] \& Cotet, C[ostel] E[mil] (2017). The Gap Between the Knowledge of Virtual Enterprise Actor and Knowledge Demand of Industry 4.0, Proceedings of the 28th DAAAM International Symposium, pp.07430749, B. Katalinic (Ed.), Published by DAAAM International, ISBN 978-3-902734-11-2, ISSN 1726-9679, Vienna, Austria

DOI: $10.2507 / 28$ th.daaam.proceedings.105

\begin{abstract}
The alert steps of industrial digitization makes now credible the use of "Industrie 4.0" term launched by Henning Kagermann in 2011 and by most appreciations, interconnected digital technology is the Fourth Industrial Revolution. All the major innovations that occurred in digital technology require from the virtual enterprise actors a level of knowledge not so easy to be achieved. Knowledge comes in multiple forms and types (tacit, explicit, learned individually or through collective learning) and is in close link with the management of virtual enterprises. When it is absent the activity of the company will be faulty. It is very important to find the reason for the existing gap between demand and offer of knowledge and establish in what way it will affect the management of virtual enterprise. This study aims to present the level of existing knowledge versus the level of knowledge demand, how we can help increase competence, in which areas organisations can benefit from it and what type of competences we will need in the future.
\end{abstract}

Keywords: Knowledge; Management; Virtual Enterprise; Competences; Fourth Industrial Revolution

\section{Introduction}

Over the last few years there have been gradual changes towards the new technology, but from now on, there is already a difference in the peace at which things need to change. Progress awaits no one, and all that is new must be absorbed as fast as possible. Virtual organizations are at the point in which all the strategies must be reorganized in order to keep up with the new demands coming from Industry 4.0: better knowledge, better and new specializations, soft skills, management and communication skills.

The intensive development of computer technology and industry or telecommunication services over the past decades has led to a better outreach of the information society. A society of this type is clearly dependent on artificial intelligence, virtual environment and the evolution of industrial society, to the informational, through computerization, is a trend of contemporarily clearly characterized by global expansion, rapid change and the social system revolution, while the social 
and economic environment, with the help of cross-border information, tends towards a globalization process that will have a strong positive impact on information technology and communications. [7] Gradually, the way of access to information and public information resources will be very diversified in all areas nowadays, from government to culture or education, will create new jobs and a significant increase in occupation.

Information resources and knowledge will take on a very large and high degree of importance. Research and technological innovation activities will play a key role in economic and social development. The economic sector that deals with the production and dissemination of information assets will feel an increased dynamics, and computer-assisted activities, interactive work, remote work within virtual organizations (where occupants of various geographic territories will overcome geographical barriers) will become predominant. A major share will be held by virtual enterprises and distance learning. [8]

An informational society is based on an intensive technology-information economy and provides information-based businesses with the utmost use of material and human resources through a high intelligence investment. This type of economy leads to a wide range of IT products and easy citizen access to information system facilities, both in workplace and private life. The infrastructure of this society is represented by computer networks, telecommunication, intelligent workstations, expert teams and systems or multimedia systems that become operational, integrating information (be it text, sound or image) to assist the process of access to knowledge, designing new ideas and making decisions.

Technologically advanced development must be sustainable and qualitative, therefore limited natural resources, environment and society, all need to be protected by applying appropriate industrial policies and implementing new strategies to support the education and training system research. We are witnessing the development of Industry 4.0 and all changes and forms of organization or reorganization imposed by it.

The current innovation potential of the companies involved in the production will ensure competitiveness, maintenance and development in the future. Post-industrial society is progressing from a technical and technological point of view, and highly developed countries tend to deindustrialize, transferring the areas of labor-intensive activity to emerging states. But there is a problem: can the service industry provide enough work to balance the growth of industrial strength and productivity as a result of automation and robotics? In the last decades, the new information technology has had a huge impact and decentralization, reorganization requires more and more accessible information to the management of organizations and enterprises, and to top or middle managers. The service market is over-saturated and competition in the field is getting stronger.

There have been changes in many areas such as e-government, e-commerce, education (e-learning), culture (multimedia and virtual libraries), setting the transition to a new industrial revolution based on the progress of knowledge, innovation, discoveries and new technologies. As the gradual evolution of science, the emergence of important inventions, and the desire of the people to evolve have generated major changes and have always led to industrial revolutions, the development and evolution of technology, technology in general, information and communication technology in particular the beginning of the Fourth Industrial Revolution we are currently witnessing: Revolution 4.0.

This Industrial Revolution is characterized by the development and use of green energies, the strong impact of the Internet, the spread of robotics, biotechnology, nanotechnology, microelectronics, the emergence of advanced materials and additive production (3D printing).

Internet development has led to a change in the way goods and services are offered. It has moved from direct trade to online commerce, thus facilitating access to information and communication by both companies and consumers.

As a result of all changes in the field of information and communication technology, there is a need for a different form of business organization at the functional level, namely the one we currently call a virtual organization. As a result of the changes in the economic and industrial environment, the possibility of a new form of organizing business and production at the institutional level was identified: the virtual enterprise.

At the same pace as society, technology and industry change, the way in which businesses operate and is organized is changing. In order to be present in the current climate of technical and technological progress, we see the emergence of virtual organizations, virtual teams and virtual organization of enterprises and the need for a better level of knowledge and knowledge management.

\section{Literature review}

Every few years, a new technological development or managerial philosophy attracts the attention of thinker's strategic organizations and business practice. Not long ago, it was conceptualized and developed "Total quality management", then "redesigning Business Process Reengineering". More recently, a new interest emerged for "Knowledge Management", although as early as 1950 Peter Drucker introduced the concept of "knowledge Workers" for workers capable of using knowledge in the organization to produce intangible products. Because the market has become more competitive and less predictable, organizations realized that their main values are what they know and using the knowledge on technologies, organizational processes, in order to obtain the competitive advantage [2]. If the industrial society has different types of organization, coordination, planning of technological resources, products and financial resources in the informational company or knowledge-based approach is pursued finding principles, methods and techniques of investigation, planning, organizing the critical resource-knowledge [12]. There is no standard definition regarding all that stands for knowledge. It generally refers to a set of organizational practices and ways of generating, capture and disseminate the necessary knowledge to achieve objectives of the organization. 
There is a lot of confusion about differences between time, information and knowledge. While the data reflects the numerical description of some actions, processes, facts, phenomena, information bring an increase of knowledge reflecting a set of data grouped in some models and forms, and knowledge groups a set of information with a strong human and contextual determinant. In this sense, the knowledge describes an ensemble of information acquired or applied to a particular context through human thinking. A significant difference between information and knowledge is determined by the transfer them. While the information can be easily transferred from one person to another, knowledge has a lower degree of transferability, they also have a psycho-social content, contextually reflecting intuition, creativity and experience the person who possesses this knowledge. [13]

Nonaka and Takeuchi identify the following types of knowledge [9], [10], [11]:

- Explicit knowledge that can be expressed through words and numbers. It can be easily communicated and distributed under form of data, scientific formulas, coded procedures or universal principles.

- Tactical knowledge that is very personal and difficult to understand by formalized, experience-dependent and featurerich individuals.

- Implied knowledge stored in entities that depend on the practical context (products, technologies, processes etc). The value of knowledge is reflected in products and physical services of the organization in intellectual products (patents and licenses), processes (structural capital) and people (intellectual capital).

In the view of the authors these are the main characteristics of knowledge:

- Is an abundant resource that develops continuously. While world evolves, human knowledge develops. With the help of information and communication technologies, methods innovation and generation of ideas, this resource can have a special momentum [1].

- The benefits of a good knowledge management can be very high. In an organization with 1000 people we don't actually have 1000 people who develop and share their knowledge possessed, but the ones that do are a great asset.

- The transfer of knowledge and information is not subject to laws, taxes and trade barriers. It assumes a lower cost of this resource.

- Knowledge is contained in information packets. They cannot be assimilated to information that is perceived in seconds. Knowledge is assimilated in days and weeks by reading, listening, experience or human interaction.

- Knowledge about work can be learned through work - during practical exercise, behind reflections on mistakes and the success of the process.

- Knowledge is generative. Knowledge about a domain involves not just reproduction of information which characterizes that area, but the enunciation of some Knowledge that requires correlations, abstractions and syntheses. Human knowledge thus becomes the most important production factor that can provide organizations and nations, competitive advantage in the new millennium [3].

Human knowledge practically embraces all structures and its processes: organizations, technologies, products, human resources, being the foundation structure of an organization.

Translating human knowledge into manageable entities, which can be effectively acted through different actions and practical tools have spurred the emergence of a theory regarding the management of knowledge, which can be defined as the art of predicting, manage and develop the knowledge of a socio-human system in order to achieve the objectives.

\section{Existing knowledge and knowledge demand}

To offset the rapid pace with which industry and society in general are moving towards adopting Industry 4.0, we need to balance between knowledge needs and current knowledge. The limitations of this research and the authors approach are related to the knowledge and the knowledge gap between the existing level and the level required.

Managing knowledge is the process by which the starting knowledge that exists in a company is organized and coordinated. This process involves:

- Grouping knowledge by type from the main sources of the organization, through processes, to building internal memory. The group is considering different criteria set by knowledge system designers.

- Storing the knowledge that is being pursued in knowledge infrastructure organization in terms of efficiency.

- Classification of knowledge for evaluation and award priorities that reflect the quality of knowledge, respectively the degree of suitability to process requirements.

- Selection of knowledge by which the user is allowed using criteria to identify the most appropriate ones.

- Dissemination of knowledge through which knowledge is stored in various forms (tacit, explicit or implicit) and accessed by all members of the organization and even by its stakeholders - customers, suppliers, etc. The knowledge management process has developed mostly based on technology systems information and communication.

Knowledge development refers to the accumulation of new knowledge for innovation, adaptation and achievement objectives of the organization. Forms of knowledge accumulation vary depending on the entity that accumulates them. Human resources accumulate knowledge through socialization (human interaction), explicit internalization (learning in formal or informal framework) and implicit internalization (carrying out work processes, or by doing). Artificial intelligence systems accumulate knowledge by processing new facts in the context determined by an initial knowledge base and a model of thinking. The organization, viewed as a learning entity organization, modifies its potential actions in a given context. The rhythm with which an entity learns to anticipate and adapt to environmental developments is a source 
of competitive advantage [4]. The organization accumulates knowledge from outside by renting (hiring a consultant and using his expertise for acquiring new acquaintance) or by buying (purchasing a society for the knowledge it holds) or from inside, through the dissemination of it from a particular source component and the development of existing sources. An important aspect of development is the process of converting implicit knowledge (from the practical environment) into tacit knowledge (related to the resource human) through the exercise of work processes. Efficiency of this process is determined by the mental model or the way of thinking of the individual, his previous knowledge and the practical context [14]. The role of each of these factors can be deduced from the following analogies: the context is practically analogous to the raw material supplier; mental model is analogous to the technology of transformation the raw material, and previous knowledge has the role of the catalyst which allows the raw material to be transformed. The mental model is the result of the accumulation and is considered the most important factor in the process development. In the theories of knowledge management there have been delimitated two types of knowledge mental models: linear thinking and systemic thinking. Studies on the two models of thinking reveals that systemic thinking allows efficiency and high efficacy of human decisions in professional or social life. By systemic approach the system is building decisions that can balance the negative effects of decisions that are taken in the case of linear thinking. Previous knowledge may be characterized by volume, structure and quality. The higher the volume of the platform on which new knowledge can be built and the better the structure or diversity of knowledge is, it contributes to building deeper knowledge. Quality acquaintance reflects the ability to respond more effective to practical needs; the more knowledge more appropriate to practical needs we have, both accumulation is intensifying. The practical context has the role of providing its information the knowledge that represents the substance necessary for the accumulation of new; through its dynamics, the practical context determines new connections and new knowledge, respectively.

It is in our belief that new specialist are needed for managing different tasks: knowledge transfer experts (people who extract knowledge from different sources, organize and them so that anyone can use it and update them periodically); strategies experts for knowledge management (people that develop the strategies related to the knowledge base - auditing knowledge sources, determining what requirements derives from the mission, purpose and objectives assumed, the strategic planning of the necessary knowledge etc.); knowledge designers (people with concerns similar to the specialists who have developed for two decades rules and facts for expert systems; in this new profession, designers of knowledge follow design rules and the knowledge base at the whole organization); knowledge management Officers (responsible with the creation of knowledge infrastructure, structures and related processes and organized organizational culture for learning and acquiring knowledge) [5].

We need knowledge-based technologies. Intranet represents the Internet concept within an organizations : each entity, individual, compartment, office, working groups, other formal or informal structures have its own web page thus allowing access via the Internet to the information and knowledge dispersed within organization. The intranet also contains a page web with access to the central knowledge of the organization. This form of network uses Internet infrastructure and leads to minimal resources needed for its design. Navigation can be done with Netscape navigator or other specialized browsers. Employees of the company can thus be in permanent contact with organization and with its knowledge base from any point on Globe through the Internet. Groupware is the information technology that drives of group words and software, which means software for group work or in other words, knowledge and software accessed at the same time by multiple users. Most relevant construction of the software market is Lotus Notes, often used for brainstorming and electronic teleconferences in the process of generating and disseminating new knowledge. Document management software is a product computer system that allow the integration of entities within the documents as well as on-line access to them. Open distributed hypertext systems are software programs that allow embedding of components information technology - text, graphics, audio and video - which are also distributed via virtual network connections computers. The Internet is such a hypertext system distributed but are read-only, not open as webpages are.

Technologies and techniques of representation of knowledge through which knowledge is considered object between which different connections are established are in full swing development due to the emphasis on explicit knowledge. It is appreciated that the hypertext distribution through virtual connections between the components of an entity is the most used representation technique and will be more and more used.

Already exist in the world processes that help increase knowledge competence modeling. One of those is the process of analysis for organizational identification of specialists and their competencies, profile design (knowledge, values, aspirations, behaviors and attitudes) and development competencies in the directions needed to support the areas critical of the organization. The memory of the organization is the process that has as abjective the transformation of silent knowledge from within the organization in explicit knowledge, easily transferable. The existence of internal memory allows the application of contestant practices engineering, rapid adaptation to environmental changes outside and the formation of virtual organizations in which components are horizontally integrated. Communities of knowledge practice are communities of experts, practitioners, politicians, teachers and researchers etc. which share a common interest in certain themes. They use in general an electronic platform, to develop concepts and debate issues in discussion. Benchmarking is the managerial practice with the role of investigate best practices from different industries and organizations and report the organization's internal processes to the new standards.

We have to develop national design policies for a knowledge-based economy. Most of the countries OECD have begun building the human infrastructure and informational technologies that will translate economies to the new knowledge-based society. The main competencies on which these policies are focused: production of knowledge, transmission, transfer and measurement of knowledge. 
Organizations are increasingly focusing on their intellectual assets, and less on the material goods they have administered. Knowledge solutions become the key used to build and support capital goods and they are used to create economic value and enable individuals, teams, and communities to achieve much improved performance in creating, capturing, sharing, and exploiting knowledge [6].

\section{Conclusion}

It is necessary to clearly delimit the concepts of data, information and knowledge. Data is a series of directly observable properties of things, information is the accumulation of data in a higher-level beam with meaning filtered through a person's perceptions and thoughts (cognition), information stimulates one wide range of actions and activities and knowledge is extracted from data and built on information. The two distinct forms of knowledge : explicit knowledge, consisting of forms of information, expertise, or experience that can be expressed in detail, archived, encoded, and can be distributed with IT and can take the form of a database, a document, a drawing, formula, patent, video, or presentations and silent knowledge, or intrinsic science, the ability of an individual to possess, is a system Common, unexpressed values, visions, goals, and behaviors that direct the activities of an organizations; the tacit knowledge derives from the accumulated experience.

The main obstacle for most organizations is identifying this tacit knowledge system. Challenge raised by this consists of finding out how to recognize, generate, distribute, and administer the system. Tactical knowledge can only be deduced from human actions, it is are not observable directly. It is a human attribute that predisposes people to act in certain ways depending on circumstances. An accumulation process can use and re-use information, explicit knowledge, experience, and expertise to obtain a special business benefit, meeting a goal, or to increase the profitability and competitiveness of the organization. Through this process, an organization generates value from intellectual and goods based knowledge. Knowledge management is a good catalyst for innovation and learning. Solutions in this area have the duty to fill the gap between explicit and tacit knowledge and implement content technologies that support the capture and management of explicit information. Collaborative technologies allow individuals and communities to create, distribute, and publish information to meet the specific business objectives.

The gap between existent knowledge and demanded knowledge must be filled. In order to do that, organisations need a good knowledge management. We think that in today's economic climate, where the focus is on information, organizations get greatest value from their intellectual goods rather than from physical ones. They have to maintain the sharing of knowledge to lay the foundations for collaboration. In addition, a good management of it narrows the gap and helps organizations in the following areas:

- Supporting innovation - provides a network infrastructure electronic and social, so that they can develop new products or services; it supports and provide access to sources of ideas so that they can be transformed into capital.

- Supporting collaboration - enhances opportunities for collaboration; this enriches the exchange of tacit and explicit knowledge among people; and encourages free flow of ideas.

- Encouraging and using learning - facilitates and accelerates the learning process; it creates for individuals and groups the possibilities to implement new knowledge; it exploits organizational knowledge and brings the right knowledge to the right people, in an intelligible context that explains the new challenges; it capitalizes on individual learning through rewarding and speculating on the benefit of the entire organization.

- Developing social capital - enhances the transfer of individual knowledge within the organization; supports the exchange outside the organizational boundaries, and puts together the people who have the necessary tacit and explicit knowledge to carry out their work.

- Attracting and Maintaining Human Capital - increases storage rates employees by recognizing the value of each employee's knowledge and rewarding it for this luggage; capture and capitalize people knowledge; promotes career development.

- Creating and using structural capital - transforms intellectual capital in structural capital; and directs strategic thinking towards capitalization of knowledge above focus on budget issues.

- Creating the opportunity for online government - provides a basis IT-enabled information technology to enable citizens and customers to access the information and services they need; it establishes a network of well-trained government employees which can increase value for citizens and customers.

- Increasing productivity - fluidizes operations and reduces costs, risks, learning curves and initialization times by eliminating redundant or unnecessary processes; it contributes to the fundamental goals / mission.

- Exchange of good practices / processes - distributes good practice throughout within the organization; it learns from the failed efforts; provides a platform for innovation and innovation reuse of knowledge; sets the benchmarks for internal and external performance for individuals and teams and helps new employees become more familiar with the culture of the organization.

- Increasing customer satisfaction - improves customer service through cutting response times; it focuses on the knowledge of the needs of the customer in viewing the efforts of an organization; and improves customer experiences and results With regard to the services that are available to them.

- Establishing a distinction between competitive advantage and the business market - helps to ensure the superiority of knowledge; when it takes the form of a proposal business, products or services, it changes the proposal to capitalize on 
the supply of goods and services to provide knowledge and expertise for these goods and services and concentrates on customer needs to meet business / mission goals.

In creating innovative products and services, some organizations may not have the ability to plan in the way effectively and strategically, access the operation, and be able to successfully implement the systems needed for the business. These can become obstacles to implementing a good knowledge management.

Some of the other problems regarding the gap between demand and offer in terms of knowledge include:

- Recruitment of employees - a culture that recognizes silent knowledge and encourages employees to make exchanges is critical for good management. Employees are encouraged to give up their knowledge and experience - the features that define their value at individual level. In addition, employees who participate have the opportunity to become aware of the quality or relevance of the information they contribute with.

- Using technology to deliver optimal output. Knowledge is not focused on technology. That's why an organization should not be attracted to the trap of establishing a knowledge management program exclusively on the premises designed by a collaborative tool. Technology can support knowledge management, but this is not the starting point.

- Lack of a specific business goal - managers must incorporate a specific business goal.

- Ensure updating in the knowledge process. Content of a program must be permanently updated, rectified, or deleted. In addition, the relevance of knowledge at some point changes, just as skills employees do.

- Changing information into knowledge. Organizations must be vigilant about overloading with information. The goal of is to filter and spread the most valuable knowledge from a true ocean of information.

If we think about solving problems and about the future needs here are 10 competencies a virtual enterprise actor will need at work after 2020 in order to meet any knowledge demand:

- Flexible thinking - the ability to give up ineffective actions and solve problems in a way that will lead to the desired results, the ability to approach new strategies easily, to see the situation in development and to predict the outcome of different variants, the ability to select information and find solutions by using a variety of approaches;

- Negotiation - the capacity to find the solutions in which both parties gain, the ability to create a compromise that both parties benefits from, excluding imposing the view on others;

- Service-oriented - that competence that facilitates the provision of the best service, using existing resources in a shorter time. This means acting proactively and having the ability to observe both the details and the ensemble, that is, to work in such a way as to avoid the occurrence of problems, to keep the person informed about how to process the problem solving process, to have the ability to use the information you have in the most efficient way and to ensure that the service you offer has the impact you have planned;

- The ability to discern and make a decision - a complex package of interconnected competences, such as the ability to perceive and distinguish the details of a situation, the ability to follow a cognitive process of analysis and selection of conclusions, the ability to formulate an opinion or make a critical distinction on ideas, people or situations, the ability to evaluate, compare and deliberate;

- Emotional Intelligence - the capacity to manage your own emotions and correctly identify the emotions of others, the awareness of inner states and effective social interactivity;

- Coordination with others - the ability to organize your own activity by linking it to the whole package as part of it, the ability to cope with obstacles and to keep moving towards reaching the goal, separating tasks and correlating them with work, the ability to prioritize activities so as to ensure logical, fluid performance in relation to the entire package to which it belongs;

- Ability to manage relationships with people - the ability to maximize the efficiency and productivity of interaction with others for the benefit of all;

- Creativity - the ability of man to realize the new, in different forms, to reveal special, unknown aspects of reality, to develop original paths and solutions to solve the problems and to express them in new personal forms;

- Critical Thinking - an amount of competencies that support a mental process of analyzing and evaluating an idea or situation, the ability to reflect and find a logical connection between ideas and arguments, to understand the relevance of information or knowledge, and to build new arguments, as well as the ability to distinguish between facts, opinions and judgments;

- Solving complex problems - that is, a combined use of all the above competencies.

This article represents only a beginning of the study regarding the problem of knowledge. In the following period, the authors will focus their attention on further research and completion of this study.

\section{References}

[1] Anand, N.; Gardner, H.K. \& Morris, T. (2007). Knowledge based Innovation: Emergence and Embedding of New Practice Areas in Management Consulting Firms. Academy of Management Journal, Vol. 50, Vol. 2, pp. $406-428$. ISSN $0001-4273$

[2] Drucker, P. (1998). Peter Drucker on the profession of management. Mass.: Harvard Business School Press, ISBN 0-87854-836-2, Boston, US 
[3] Foss, N. J. \& Pedersen, T. (2004). Organizing knowledge processes in the multinational corporation, Journal of International Business Studies, Vol. 35, No. 5, pp. 340-349, ISSN 0047-2506

[4] Maleki, E. J. (2003). Knowledge, industry and environment: Institutions and innovation in territorial perspective. Annals of the Association of American Geographers, Vol. 93, No. 2, pp. 523-524, ISBN 0-75463-052-8, DOI : 10.1111/1464-8306.930201412

[5] Hurt, U./, Otto, T./, Kaare, K. K. \& Koppel, O. (2014). New Approach to Knowledge Transfer Environment Development. Procedia Engineering, 24th DAAAM International Symposium on Intelligent Manufacturing and Automation, 2014, Zadar, Croatia, ISSN 1877-7058, Katalinic, B. (Ed.), Vol. 69, pp. 273-281, Elsevier Ltd., DOI : 10.1016/j.proeng.2014.02.232

[6] Kogut, B. \& Zander, U. (1993). Knowledge of the firm and the evolutionary theory of the multinational corporation, Journal of International Business Studies, Vol. 24, No. 4, pp. 625-645, ISSN 1478-6990, DOI : 10.1057/Palgrave.jibs.8490248

[7] Kurtuhuz, A.; Salisteanu, C.; Udroiu, I.; Petrescu, M.; Issa, C. \& Udroiu, F. (2014). The new organization based on knowledge and communication. Chapter 17 in DAAAM International Scientific Book 2014 Vienna, Austria, ISSN 1726-9687, ISBN 978-3-901509-98-8, Katalinic, B. (Ed.), pp. 189-196, Elsevier Ltd., DOI : 10.2507/daaam.scibook.2014.16

[8] Leber, M.; Buchmeister, B. \& Ivanisevic, A. (2015). Impact of knowledge on innovation process. Chapter 21 in DAAAM International Scientific Book 2015, Vienna, Austria, ISSN 1726-9687, ISBN 978-3-902734-05-1, Katalinic, B. (Ed.), pp. 235-248, Elsevier Ltd., DOI : 10.2507/daaam.scibook.2015.21

[9] Nonaka, L. \& Takeuchi, H. (1995). The knowledge creation company: How Japanese companies create the dynamics of innovation. Oxford University Press, Oxford, New York, ISBN 0-19-509269-4

[10] Nonaka, L. \&Takeuchi, H.; \& Umemoto, K. (1996). A theory of organizational knowledge creation. International Journal of Technology Management, Vol. 11, No. 7-8, pp. 833-845, DOI : 10.1504/IJTM.1996.025472

[11]Nonaka, L. \& Takeuchi, H. (2011). The wise leader. Harvard business review, Vol. 89, No. 5, pp. 58-67, ISSN 00178012

[12] Rodgers, P.A.; Caldwell, N.H.M.; Hoxor, A.P. \& Clarkson, P.J., (1999). WEBCADET: a knowledge management support system for new product development, In : 6th International Product Development Management Conference, Cambridge University Press, pp. 937-948, Cambridge/UK

[13] Welbourne, M. (2002). Knowledge. Taylor and Francis, Chesham, Acumen

[14] Wouters, P.; Beaulieu, A.; Scharnhorst, A. \& Wyatt, S. (Eds.). (2013). Virtual Knowledge: Experimenting in the Humanities and the Social Sciences. MIT Press. Available from http://www.jstor.org/stable/j.ctt5vjrxn, Accessed : 2016-10-15 